\title{
POLÍTICAS PÚBLICAS BRASILEIRAS EM FAVOR DA EDUCAÇÃO INTEGRAL: AVANÇOS E DESAFIOS
}

Samantha Schäfer ${ }^{1}$

\section{Resumo}

Este artigo debate as modificações do tempo de escola no Brasil, a partir da Constituição de 1988, a confirmação, pela sociedade, da necessidade de se construir uma nova identidade para a escola pública através do surgimento de políticas públicas relacionadas a Educação em Tempo Integral, com ênfase especial no programa Mais Educação e seus desdobramentos. Primeiramente há uma discussão sobre o contexto do país em que a proposta da Educação em Tempo Integral surge, além da diferenciação entre Escola Integral e Escola em Tempo integral. Em seguida é debatido o tempo da escola e de que maneira justifica-se a ampliação desse tempo diário escolar e sua relação com a qualidade do trabalho educativo.

Palavras - chave: Educação em tempo Integral, políticas públicas, funções da escola, qualidade.

\section{Abstract}

This article discusses the chances of school time in Brazil, starting with the 1988 Constituition, the validation $b$ society of the need to build a new identity for the public school through the emergence of public policies related to full time education, with special emphasis in the more Education program and its developments. Firsthy, there is a discussion about the context of the country in which the proposal of Integral Education arises, besides the difference between Integral School and Full Time School. Next, the time of the school is debated and how it is justified the expansión of this daily school time and its relation with the quality of the educational work.

Keywords: Full time education, public policies, school functions, quality.

\footnotetext{
${ }^{1}$ Professora, Mestrando Acadêmico Internacional em Educação da Universidad de la Empresa - UDE, Montevidéu Uruguai. Seminario Culturas, Saberes y Prácticas. samanthaschafer@hotmail.com.
} 


\section{CONTEXTO HISTÓRICO-SOCIAL E EDUCACIONAL BRASILEIRO}

No decorrer do século $X X$, o tempo de escola em nosso país vem sofrendo lentas mudanças na definição, parece estar se somando com um novo tempo social que se desenvolve de acordo com as modificações da cultura urbana, que incorporou a escolarização das massas, o ingresso das mulheres no mercado de trabalho, a tentativa de eliminaçãoo do trabalho infantil, e a regulamentação das relações trabalhistas. E com a obrigatoriedade escolar veio sendo consolidada uma nova ordem no âmbito social, pela exigência crescente dos mais altos níveis de escolaridade, de profissionalização dos professores e padronização dos sistemas nacionais de ensino.

Vive-se no Brasil um tempo importante para e educação do nosso povo, desde os esclarecimentos contidos na Constituição Federal de 1988, a população brasileira, em geral, adquiriu uma maior consciência dos direitos sobre a educação pública de qualidade para todos. Em nível nacional está se implementando uma escola pública republicana, laica, obrigatória, gratuita e integral.

Nesse contexto, percebe-se o aumento de projetos na educação básica pública, que tem como característica marcante a jornada em tempo integral. Mesmo antes de $1988 \mathrm{com}$ a abertura houve projetos englobando essa prática, como os CIEPS (Centros integrados de Educação Pública, no Rio de Janeiro. Mais à frente, com a virada do século, com base no artigo 34 da Lei de Diretrizes e Bases de 1996, houve uma preocupação maior no aumento do tempo diário de permanência das crianças e adolescentes nos sistemas públicos estaduais e municipais.

Art.34. A jornada escolar do ensino fundamental incluirá pelo menos quatro horas de trabalho efetivo em sala de aula, sendo progressivamente ampliado o período de permanência na escola.

1. São ressalvados os casos do ensino noturno e das formas alternativas de organização autorizadas nesta Lei.

2. O ensino fundamental será ministrado progressivamente em tempo integral, a critério dos sistemas de ensino.

Nas disposições da referida lei asseveram no artigo 87, parágrafo 5, que "serão conjugados todos os esforços objetivando a progressão das redes escolares públicas urbanas de ensino fundamental para o regime de escolas de tempo integral (BRASIL, 1996). Contudo, a Lei de Diretrizes e Bases deixa a critério dos sistemas de ensino o planejamento e as decisões referentes a implementação do tempo integral. 
Essas políticas públicas, desvelam a percepção, por parte da sociedade, de que há a necessidade de se construir uma nova identidade para escola fundamental, primeiramente a integração efetiva de todas as crianças à vida escolar. Nessa escola, se busca um novo formato, que além da instrução escolar seja também presente uma forte ação na integração social, no desenvolvimento da socialização. A busca de uma nova identidade sócio-cultural para a escola não pode se acabar em seus temas internos, está fundamentalmente, ligada a um projeto mais amplo de sociedade.

Com esses novos obbjetivos há a ampliação das funções da escola que surge como imposição da realidade em que vivemos e não por uma decisão política deliberada.Inúmeros sistemas estaduais e municipais do país, em cumprimento à legislação, tem gradativamente implantado a organização da escola em tempo integral, com o incentivo do Governo.

\section{POLÍticAs PÚBLICAS EM FAVOR DA EDUCAÇÃO EM TEMPO INTEGRAL}

De acordo com Moll (2009), desde 2007 há movimentos realizados pelo Ministério da Educação em direcionar a educação brasileira na construção de políticas em favor a Educação Integral, entre elas destaca-se:

Condições para a transferência voluntária de recursos pela União: a publicação anual das resoluções do programa dinheiro direto da escola (PDDE), do Conselho Deliberativo do Fundo Nacional de Desenvolvimento da Educação (FNDE) proporciona o repasse de recursos financeiros diretamente as escolas de acordo com a situação das Unidades Executoras das escolas em relação a prestação de contas. Há ainda, o direcionamento do Programa Mais Educação com o Programa Nacional de Alimentação Escolar (PNAE), que se amplia recursos diários per capita de alimentação para estudantes em tempo integral.

A construção de estratégias comunicativas presenciais e virtuais com as secretarias de educação e suas redes de ensino: é a forma institucional que permite que haja uma rede de reforço e de execução do Programa Mais Educação, já que, na perspectiva da educação integral em tempo integral necessita constante diálogo entre o MEC (Ministério de Educação e Cultura), as equipes gestoras do Programa Mais Educação nos Estados e Municípios e as escolas envolvidas. Há a criação de espaços de debates, seminários, reuniões, fóruns de todas as esferas todos em confluência com o tema escola em tempo integral (incluindo desde a operacionalização, alimentação, infraestrutura ao corpo docente). 
Melhor distribuição do debate na sociedade brasileira: desde a última Constituição há a preocupação com os debates públicos com o intuito de melhorias na produção de textos de referência nacional para o debate da Educação Integral, englobando a participação de gestores e educadores municipais, estaduais, e federais, representantes da União Nacional dos Dirigentes Municipais de Educação, do Conselho Nacional dos Secretários de Educação, da Confederação Nacional dos Trabalhadores em Educação,da Associação Nacional pela formação de profissionais da Educação, de organizações não governamentais comprometidas com a educação. Há um aumento de envolvidos nos debates, devido a participação de atores de Comissões de Educação das diferentes esferas legislativas, Conselhos de Educação e outros representantes da sociedade civil.

Estrutura física e pedagógica: Na execução do Programa Mais Educação questiona-se de que forma a escola tem se organizado em sua estrutura física e na dinâmica com outros espaços para a devida ampliação de tempos e oportunidadeseducativas na concepção de Educação Integral.

Oferta da Educação Integral em articulação com o Programa Bolsa Família: para a adesão de 2012, o MEC (Ministério da Educação e Cultura), em parceria com o Ministério do Desenvolvimento Social e Combate a Fome (MDS), estabeleceu como critério principal para expandir o programa Mais Educação a seleção de escolas em que a maioria dos alunos faça parte de famílias que se beneficiam do Programa Bolsa Família. Esse acordo foi realizado em Brasília em dezembro de 2011, com a participação de dez coordenadores estaduais do Programa Bolsa Família e representantes estaduais e municipais dos Programas de Educação Integral aqui retratados. Confirma-se assim, a educação integral como um recurso de enfrentamento das desigualdades encontradas no país. Já que, preferencialmente, as escolas atendidas são as das regiões periféricas e mais vulneráveis. Essas escolas recebem orçamentos diversificados e ainda são prioridades na inter-relação com as universidades que participam desse processo de interação em ações de formação para a docência e a gestão.

Entrelaçamento de redes humanas e redes institucionais: refere-se a mobilização de forças necessárias para dar impulso às políticas públicas que estão surgindo, os processos e movimentos sociais que se transformam em ações de educação integral e intenções por uma escola republicana, democrática e de qualidade. Nessa perspectiva, necessita a construção da autonomia da escola, uma relação estreita entre escola e comunidade, espações educativos diversificados (dentro e fora da escola). Todos os atores envolvidos em um esforço para compreender, discutir e enfrentar dos desafios cotidianos da escola integral. 
Relação das políticas curriculares e a proposta das diretrizes curriculares na educação integral: a experiência relacionada a ampliação da jornada escolar, no Programa Mais Educação, poderá contribuir tanto no compartilhamento de uma política pública, quanto em relação ao currículo escolar que legitime saberes e práticas sociais e culturais, que nem sempre estão atrelados a escola. E dessa forma, a ampliação do tempo escolar, otimiza-se a medida em que articula atividades educativas distintas, e assim contribui, efetivamente, para a formação integral do aluno.Moll(2009), ainda nos afirma que a extensão do tempo (quantidade), deve ser acompanhada por uma intensidade do tempo (qualidade) nas atividades que constituem a jornada ampliada na instituição escolar.

Uma educação integral em uma escola de tempo integral, pode, com sucesso, demonstrar as condições diferenciadas para que tomem consciência e aprendam, no interior das escolas, aqueles indivíduos cujos pais, de alguma forma, foram excluídos socialmente em decorrência da obrigação de produzir seu sustento, e, reproduzindo eles mesmos, a condição de seus pais nas regiões mais pobres do país.

Houve um esforço realizado através do governo federal com o Programa Mais Educação nos últimos anos na educação brasileira, na mobilização de lideranças educacionais e estrutura orçamentária visando a construção de práticas pedagógicas que levem a um caminho a educação integral, para que o papel da instituição escolarefetive-se democraticamente na sociedade brasileira e possa tomar partido no combate as injustiças sociais.

As políticas de Educação Integral e em tempo integral foram invocadas na primeira década dos anos 2000, pois foi reconhecido como política relevante para o enfrentamento das desigualdades educacionais e por consequência, das desigualdades sociais. A educação integral engendrada pelo programa mais educação é desenvolvida pelo Ministério da educação em parceria com estados e municípios, que solidifica a inclusão da educação integral e em tempo integral na rotina das políticas educacionais do governo brasileiro.

Segundo o portal do MEC (Ministério da Educação e Cultura) o Programa Mais Educação é:

Instituído pela Portaria Interministerial no 17/2007 e regulamentado pelo Decreto 7.083/10, constitui-se como estratégia do Ministério da Educação para induzir a ampliação da jornada escolar e a organização curricular na perspectiva da Educação Integral. As escolas das redes públicas de ensino estaduais, municipais e do Distrito Federal fazem a adesão ao Programa e, de acordo com o projeto educativo em curso, optam por desenvolver atividades nos macrocampos de acompanhamento pedagógico; educação ambiental; esporte e lazer; direitos 
humanos em educação; cultura e artes; cultura digital; promoção da saúde; comunicação e uso de mídias; investigação no campo das ciências da natureza e educação econômica.

A proposta das atividades de educação integral, segundo o MEC ( Ministério da Educação e Cultura) compreendem estratégias para o acompanhamento pedagógico diário da aprendizagem dos estudantes quanto às linguagens, à matemática, às ciências da natureza, às ciências humanas; bem como quanto ao desenvolvimento de atividades culturais, da cultura digital, artísticas, esportivas, de lazer e da abertura das escolas aos finais de semana.

A reorganização curricular e a ampliação das dimensões que constituem a ação pedagógica fomentadas pelo Programa implicam em possibilitar a garantia do direito à aprendizagem significativa e ao desenvolvimento desses estudantes. Desta forma, diz respeito aos processos socializadores e formadores amplos, envolvendo práticas que desenvolvem as múltiplas dimensões humanas - cognitiva, psicomotora, sócio afetiva, estética e ética - e incentivam a construção de projetos de vida. O Programa Mais Educação constitui-se como estratégia do Ministério da Educação para indução da construção da agenda de educação integral nas redes estaduais e municipais de ensino que amplia a jornada escolar nas escolas públicas, para no mínimo 7 horas diárias, por meio de atividades optativas nos macrocampos, são elas:

Acompanhamento Pedagógico (obrigatório); Comunicação; Uso de Mídias e Cultura Digital e Tecnológica;Cultura; Artes e Educação Patrimonial;Educação Ambiental, Desenvolvimento Sustentável e Economia Solidária e Criativa/Educação Econômica;Educação em Direitos Humanos;Esporte e Lazer e,Promoção da Saúde.

Para as escolas rurais, os macrocampos disponíveis são:Acompanhamento Pedagógico (obrigatório);Agroecologia;Iniciação Científica;Educação em Direitos Humanos;Cultura, Artes e Educação Patrimonial; Esporte e Lazer; Memória e História das Comunidades Tradicionais.

\section{RELAÇÃO ENTRE A QUALIDADE DO TRABALHO EDUCATIVO E O TEMPO DE ESCOLA}

Comecemos com o conceito de educação de Anísio Teixeira (2007, p.100) como base sobre a educação ele nos diz:

Temos, primeiro de tudo, de reestabelecer o verdadeiro conceito de educação, retirando-lhe todo o aspecto forma, herdado de um conceito de escolas para o 
privilégio e, por isto mesmo, regulados apenas pela lei e por toda sua parafernália formalística, e caracterizá-la, enfaticamente, como um processo de cultivo e amadurecimento individual insusceptível de ser burlado, pois corresponde a um crescimento orgânico, humano, governado por normas científicas e técnicas e não jurídicas, e a ser julgado sempre a posteriori e não pelo cumprimento formal de condições estabelecidas a priori.

Reestabelecida esta maneira de conceitua-la, a educação deixará de ser campo de arbitrária regulamentação legal, que no Brasil, vem fazendo dela um objeto de reivindicação imediata, por intermédio do miraculoso reconhecimento legal ou oficial. O fato de havermos confundido e identificado o processo educativo como um processo de formalismo legal levou a educação a ser julgada por normas equivalentes às da processualística judiciária que é, essencialmente um regime de prazos e de normas fixados, de certo modo, por convenção.

A partir dessa definição pode-se inferir que é na perspectiva da Escola Integral, que se pode retomar o sentido desse crescimento humano, pois associa-se as inúmeras dimensões do desenvolvimento humano.

Há um interesse tanto nacional quanto internacional a respeito do tema da escola em tempo integral, faz parte do conjunto de reflexões sobre a qualidade da educaçãona escola. A institucionalização desse chamado da população por uma escola integral, envolverá escolhas, decisões políticas, quer dizer, tanto poderão ser desenvolvidos os aspectos criativos com inovações, com aspecto transformador engendrados em uma prática escolar rica e multifocal, como poderão ser conservadores com aspectos reguladores exagerados.

No entanto, não se deve desconsiderar, como um desafio latente, a proximidade entre os sistemas de ensino e o contexto real da escola, para a gestão escolar no que diz respeito a implementação de programas federais, subsidiados técnica e financeiramente pelo ministério da Educação. O entendimento desse aspecto, a compreensão do funcionamento do chão da escola, de toda as suas problemáticas, construção e reconstrução de conhecimentos e saberes é de fundamental importância, já que é lá que o processo de ensino aprendizagem ocorre com todos os seus nuances.

Em contraposição ao aspecto que reduz a importância da implementação de determinados projetos face ao projeto político pedagógico das escolas e redes de ensino. Moll (2009) nos adverte que, a ampliação do tempo dos estudantes na escola implica diretamente na reorganização do espaço físico, na jornada de trabalho dos funcionários, nos investimentos 
financeiros diferenciados para garantir a qualidade do ensino em tempo integral, entre outros. Moll (2009) completa dizendo:

Para além da necessária ampliação, do tempo diário de escola coloca-se o desafio da qualidade desse tempo, que, necessariamente, deverá constituir-se como um tempo reinventado que compreendendo os ciclos, as linguagens, os desejos das infâncias e juventudes que acolha, modifique assimetrias e esterilidades que ainda são encontradas na prática pedagógica escolar.

Outro aspecto essencial da educação nos dias atuais é a necessidade do respeito as diferenças ideológicas, de gênero, de raça, de classe social, e de modos de viver diferenciados. À realidade de intensa disparidade sócio- cultural, deve-se colocar um acervo cultural aberto, só será democrática a escola que permita contatos produtivos politicamente entre as distintas culturas e classes. É imprescindível que a escola seja um ambiente onde os atores escolares possam vivenciar experiências democráticas, tenham a oportunidade de expressarem seus conflitos e possam se conscientizar de acordo com novas formas culturais, para assim poder compor uma nova identidade para a escola brasileira. Já que no passado, anossa escola pública quase nunca pode assumir um papel socializador efetivo.

Torna- se pertinente aqui as exposições das ideias do pragmatista Dewey (1959), que diz que educar é tecer relações entre os indivíduos e a cultura que os envolve, de forma a se tornarem capazes de distinguir as situações, em uma cultura específica, que se exige mudança, é também torná-los em condições de agir para a realização dessas mudanças, o autor acredita que toda prática social compartilhada, tem natureza educativa. O tema central do pensamento de Dewey é a democracia, por superar a dicotomia entre indivíduo e coletividade e proporciona o desenvolvimento da inteligência (toda atividade que necessita reflexão está submetida a experiência de organização do mundo concreto relacionado as necessidades da vida do indivíduo. E para satisfazer essas necessidades se dá vivendo a interação, a experiência compartilhada. Podemos dizer que a vida de cada ser é uma teia de experiências, isto é, de aprendizagens diversas, necessita do meio social. A aprendizagem ocorre indiretamente e intencionalmente no meio social, preparado para isso.

Para tanto, vê-se a fundamental proposta de uma prática escolar com experiências reais (com fim em si mesmas) com relações interpessoais se conectando em diversos níveis e não se utilizando apenas de atividades preparatórias. 
Sendo assim, é imprescindível considerar diferenças e igualdades entre os conceitos de educação integral e escola de tempo integral. Para Cavalieri (2010), a educação integral é:

Ação educacional que envolve diversas e abrangentes dimensões na formação dos indivíduos. Quando associada à educação não-intencional, diz respeito aos processos socializadores e formadores amplos que são praticados por todas as sociedades, por meio do conjunto de seus atores e ações. (...) quando referida ã educação escolar, apresenta o sentido de religação entre a ação intencional da instituição escolar e a vida no sentido amplo.

E a escola de tempo integral, definida por Jaqueline Moll (2010) é:

Em sentido restrito refere-se à organização escolar na qual o tempo de permanência dos estudantes se amplia para além do turno escolar, também denominada, em alguns países, como jornada escolar completa. Em sentido amplo, abrange o debate de educação integral - consideradas as necessidades formativas nos campos cognitivo, estético, ético, lúdico, físico-motor, espiritual, entre outros - no qual a categoria tempo escolar reveste-se de relevante significado tanto em relação a sua ampliação, quanto em relação a necessidade de sua reinvenção no cotidiano escolar.

Dewey (1959), nos adverte que o ambiente escolar não deve ser constituído em função de objetivos fechados, mas em função de esboços de objetivos a se tentar executar, essa ideia nos remete a um projeto de escola como projeto de comunidade intersubjetiva,estruturada de forma democrática o que possibilitará, por meio das experiências vividas, a construção de uma identidade coletiva.

Segundo Cavaliere (2010), existe várias formas de justificar a ampliação do tempo diário de escola, são elas:

1) tempo maior, consequentemente o alcance de melhores resultados de exposição aos conteúdos e práticas escolares;

2) adequação da escola as novas condições da vida urbana das famílias;

3) conscientização de uma concepção do papel fundamental da escola na vida e formação dos indivíduos.

Ainda de acordo com a autora, a última das alternativas acima é a reflexão educacional mais abrangente (engloba as anteriores), traz questões a se refletir como: Que tipo de instituição 
pública de educação básica a sociedade brasileira precisa? (que funções cabem a escola, levando em conta os demais meios de comunicação e a formação para a vida democrática em sociedade).

Cavaliere (2010), conclui sua reflexão argumentando que reduzir as capacidades da ampliação do tempo de escola a busca de uma maior eficiência nos resultados escolares ou mesmo na adaptação aos hábitos urbanos da vida contemporânea reduz os possíveis significados de uma educação inovadora e criativa dessa ampliação. Para tanto, não se deve tratar a questão da ampliação do tempo escolar como uma solução para resolver os déficits da escola pública brasileira.

O tempo da escola é um dos destaques dos meios de organização do tempo social, pois é a referência para muitos indivíduos nos dias de hoje, a base para que se organize a vida das famílias e da sociedade.

O tempo é um tema complexo na compreensão de estruturas e representações sociais e de fundamental importância nesse contexto da escola integral, na teoria marxista, ele se faz presente ao determinar o valor de determinada mercadoria. Para Bourdieu (1998), o tempo agrega na formulação da noção de capital cultural. Nesse paragrafo percebemos que a medida de tempo é importante para que possamos compreender as estruturas e representações mais complexas.

O tempo não é objetivo, não se pode considerá-lo em sua substancialidade, já que ele sempre se apresenta como parte integrante entre diferentes dimensões que compõe um determinado contexto histórico. O tempo na escola deve ser considerado a partir das circunstancias históricas envolvidas, sem deixar de considerar que, em cada particularidade histórica, esse tempo de escola é função de diversos interesses (das mais distintas naturezas) que atuam sobre ele, como por exemplo: a cultura familiar predominante, o tipo de relação entre educação escolar e políticas públicas de assistência social ou de preparação para o trabalho.

Concretamente, o tempo de escola é considerado por demandas que podem estar relacionadas ao bem estar dos alunos, ou as necessidades do Estado e da sociedade ou, ainda, ao hábito e a comodidade dos responsáveis, sejam eles pais ou professores. Sendo assim, nota-se a dimensão cultural que se dá ao tempo e não nos deixa lidar comele de forma simplesmente burocrática.

Caso a escola em tempo integral apenas reproduza a escola convencional, o resultado será de maximização dos problemas de inadaptação. Culturalmente a ampliação do tempo escolar envolve outras questões peculiares ao país. Os traços da cultura brasileira chegam a concorrer com a escolarização como: a persistência do trabalho infantil, as relações de trabalhos informais. 
Segundo Bourdieu (1998), essa ampliação do tempo escolar (como escolarização com grande duração) criou a exclusão pelo interior, que o autor define como uma exclusão leve e dissimulada, pois novamente culpa o aluno por fracassar, mesmo com as inúmeras chances dada a ele. Portanto há uma afirmativa entre os professores que defendem a escola em tempo integral, que nessa perspectiva de ensino somente se justifica na medida em que propicia mudanças no caráter da experiência escolar, ao dar mais profundidade a determinados nuances dessa vida na escola.

Nos últimos anos a escola fundamental vem sendo forçada a assumir responsabilidades educacionais bem maiores do que as escolas públicas brasileiras sempre fizeram. Enquanto a educação era designada a poucos sua função primária era a de instrução escolar, porém quando ocorreu, na segunda metade do século XX, o processo de escolarização das grandes massas da população brasileira, dessa forma houve um esvaziamento das responsabilidades da escola, como: instalações precárias do ambiente físico, pela redução da jornada e aumento dos turnos, pela baixa qualidade da formação de professores, entre outros.

Com esse contexto educacional estruturado nos últimos anos, como a incorporação de diversas responsabilidades educacionais, atípicas a escola, porém, sem a qual o trabalho particularmente voltado para a instrução escolar não torna-se viável, se fez necessário o trabalho com os cuidados e hábitos primários, pois observa- se que grande parte dos alunos dependem afetivamente da escola e de seus profissionais, esses que, muitas vezes, servem de exemplo e referência primeira entre suas experiências e vida.

\section{REFERÊNCIAS}

Bourdieu, Pierre (1998) A escola conservadora: as desigualdades frente à escola e à cultura. Escritos de educação 9 pgs 41-64.

Cavaliere, Ana Maria Villel (2002) Educação integral: uma nova identidade para a escola brasileira. Educação e Sociedade 23.81 pgs 247-270.

Dewey, John (1959) Democracia e educação: introdução à filosofia da educação. Companhia Editora Nacional.

Moll, Jaqueline (2009) Caminhos da educação integral no Brasil: direito a outros tempos e espaços educativos. Penso Editora. 
(2009) Um paradigma contemporâneo para a educação integral. Pátio: revista pedagógica. Porto Alegre 51. pgs 12-15.

(2008) Caderno Educação Integral: série mais educação. Brasília: MEC,

Secad.

Parente, Cláudia da Mota Darós (2014) Educação em tempo integral e programa mais educação: aproximações e distanciamentos das regiões brasileiras em relação à meta prevista no projeto de lei do novo Plano Nacional de Educação (PNE).Contrapontos pgs 618-633.

Teixeira, Anísio (2007) Educação e a formação nacional do povo brasileiro Educação não é privilégio 6 pgs 113-182.

Titton, M. B. P. (2012). Caminhos da Educação Integral no Brasil: direito a outros tempos e espaços educativos.

Titton, Maria Beatriz Pauperio (2012) Caminhos da Educação Integral no Brasil: direito a outros tempos e espaços educativos. pgs 295-300. 